\title{
Climate change impacts on water resources and reservoir management in the Seine river basin (France)
}

\author{
David DORCHIES ${ }^{1}$, Guillaume THIREL ${ }^{2}$, Charles PERRIN² ${ }^{2}$ Jean-Claude BADER ${ }^{3}$, Régis THEPOT ${ }^{4}$, Jean-Louis \\ RIZZOLI $^{4}$, Claudine JOST ${ }^{4}$, Stéphane DEMERLIAC ${ }^{4}$ \\ 1. IRSTEA UMR G-EAU, 361 rue Jean-François Breton, BP 5095, 34196 MONTPELLIER, France - david.dorchies@irstea.fr \\ 2. IRSTEA UR HBAN, 1, rue Pierre-Gilles de Gennes, CS 1003092761 Antony Cedex France-guillaume.thirel@irstea.fr, \\ charles.perrin@irstea.fr \\ 3. IRD UMR G-EAU, 361 rue Jean-François Breton, BP 5095, 34196 MONTPELLIER, France-jean-claude.bader@ird.fr \\ ${ }^{4}$ EPTB Seine Grands Lacs, 8 rue Villiot 75012 Paris, France - eptb@seinegrandslacs.fr
}

\begin{abstract}
The Seine River Basin has to face major issues on water resources due to a variety of uses and increasing pressure. Satisfying these water needs is a huge challenge on this basin that hosts the most urbanized and densely populated area in France: more than 6.5 millions inhabitants in the Paris region are supplied with drinkable water coming from rivers while one nuclear power plant and two coal-fired plants ensure power generation in the region. Furthermore, several large wastewater treatment plants (incl. the largest one in Europe) release their waters into the Seine, with possible consequences on the quality of water during low flows. The Seine Grands Lacs basin authority owns and manages four large artificial reservoirs on the river Seine and its tributaries (totaling a capacity of $800 \mathrm{hm}^{3}$ ) with two main goals: flood alleviation and low-flow augmentation. The CLIMAWARE research project (2010-2014) characterized the impacts of climate change on flows of the Seine River Basin and on reservoir management by mid- $21^{\text {st }}$ century. Performance indicators representative of the tension on water resources were calculated to assess the impact of climate change. Various adaptation measures were tested including the modification of the objective seasonal filling curves, as well as modifications of the real-time management techniques. Adaptation measures can bring some improvements, but even with this adaptive management, the indicators show that the impacts of climate change on low flows will be major on the basin.
\end{abstract}

Key-words: Flood, Low flows, Reservoir management adaptation, Climate change impacts, Hydrological modelling, Seine Basin

\section{Impacts du changement climatique sur la ressource en eau et la gestion des lacs-réservoirs du bassin de la Seine (France)}

\begin{abstract}
RESUME. - Le bassin-versant de la Seine à Paris est caractérisé par de forts enjeux sur la ressource en eau. Les prélèvements y sont considérables : plus de 6,5 millions d'habitants en Ile-de-France sont alimentés en eau potable à partir des eaux de surface, tandis qu'une centrale nucléaire et deux centrales thermiques assurent la production électrique sur le bassin. Par ailleurs, la Seine est le milieu récepteur de plusieurs stations d'épuration (incluant la plus grande d'Europe), impliquant des enjeux pour la qualité de l'eau en période d'étiage. L'EPTB Seine Grands Lacs soutient ces enjeux avec quatre lacs-réservoirs d'une capacité de 800 millions de $\mathrm{m}^{3}$, chargés de soutenir les étiages et écrêter les crues. Le projet CLIMAWARE (2010-2014) a étudié les impacts du changement climatique sur l'hydrologie du bassin et la gestion des lacs-réservoirs à l'horizon du milieu du $21^{\text {ème }}$ siècle, en proposant et évaluant des stratégies d'adaptation de la gestion des lacs-réservoirs. Des indicateurs de performance représentatifs de la tension sur les usages (limitation des autorisations des débits prélevés, risque sur la qualité des eaux...) ont été calculés afin d'évaluer l'impact du changement climatique pour différents scénarios de gestion des réservoirs. Les mesures envisagées d'adaptation des règles de gestion des lacs-réservoirs permettent une légère amélioration des performances, mais même avec cette gestion adaptée, les indicateurs montrent un impact significatif sur les étiages.
\end{abstract}

Mots-clés : Crue, Etiage, Adaptation de la gestion de réservoirs, Impacts des changements climatiques, Modélisation hydrologique, Bassin de la Seine

\section{INTRODUCTION}

The River Seine crosses Paris and its region which totaled 11.96 million inhabitants in 2013 and $30 \%$ of the French GDP with large water uses and flood risk issues. Thus, there are critical socio-economic stakes in this basin where major high-flow or low-flow events already happened in the past

1. Corresponding author with catastrophic consequences [Ambroise-Rendu, 1997]. Besides, the ongoing climate change may have dramatic impacts on the hydrology of the basin and raises serious concerns among stakeholders.

In this context, the CLIMAWARE project (2010-2014) aimed at studying the hydrological future of the Seine River Basin. The first objective was to provide reservoir managers with an analysis framework to evaluate the possible consequences of climate change on the basin hydrological 
behavior. The second objective was to assess possible adaptation strategies they could consider in the future.

The main rivers of the basin are regulated by four large artificial reservoirs managed by the public territorial basin authority (EPTB) Seine Grands Lacs (SGL) on the Rivers Marne, Aube, Seine and Yonne, totaling a water storage capacity of $800 \mathrm{hm}^{3}$. The four reservoirs were built between the 1950s and 1980s and all the infrastructures were designed according to the known historical flood events and low-flow periods on the catchment. The reservoirs control $17 \%$ of the basin area at Paris.

Extreme hydrological events can have strong impacts on the sustainability of the system in terms of water resources (low flows) or risk (floods) and therefore are critical to study. The aim of the case study is to develop future scenarios linking the impact of climate change on water resources and the expected changes regarding the water uses and the management of the system.

The key aspects of this study are to:

- develop an integrated hydrologic/hydraulic model of the basin, including the artificial influences of dams;

- define climatic as well as socio-economic changes over the basin by the mid- $21^{\text {st }}$ century;

- evaluate the sustainability of current reservoir management rules (use of target reservoir filling curves and local reservoir constraints);

- define adaptation strategies at tactical (adaptation of target reservoir filling curves) and operational (real-time reservoir management) levels.

A special attention is put on evaluating the uncertainties linked to the different steps of the modelling chain. Dorchies et al. [2014] had presented the evaluation of the model set-up and current management rules. Here we provide additional results on the adaptation strategies and their assessment.

\section{MODELLING APPROACH}

\section{II.1. Data}

\section{II.1.1. Observed flow and climate data}

The project focuses on the Seine River Basin upstream Paris $\left(43,800 \mathrm{~km}^{2}\right)$, with 25 gauging stations spread over the main stream and its tributaries. Daily observed flow time series were collected from the national HYDRO database (www.hydro.eaufrance.fr). Naturalized flow data (1958-2009) were provided by Seine Grands Lacs [Hydratec, 2011]. They provide an estimate of natural flows, i.e. flows that would have been observed if none of the four main reservoirs had been built.

Observed climatic data (precipitation and temperature) were obtained from the Météo-France SAFRAN reanalysis [Quintana-Segui et al., 2008; Vidal et al., 2010]. SAFRAN provides daily gridded data at an $8 \times 8-\mathrm{km}^{2}$ resolution that were averaged at the sub-catchments scale. Potential evapotranspiration was computed using the Penman-Monteith formula [Penman, 1948; Monteith, 1965].

Historical management data of the reservoirs (i.e. inflow and outflow series to the four reservoirs) provided by SGL were used. Data on water withdrawals on the river basin were obtained from BIPE (Bureau d'Informations et de Prévision Economique; Office of information and economic forecast).

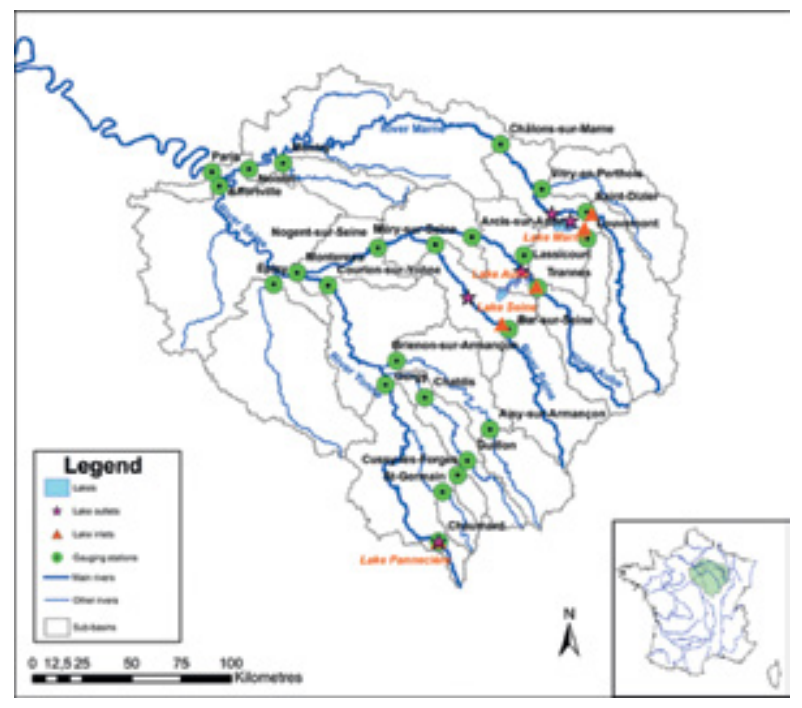

Figure 1 : Contour map of the Seine River Basin at Paris, with gauging stations, main hydrographic network and reservoirs [after Dorchies et al., 2014]

\section{II.1.2. Scenario and climate models}

Here a classical approach to derive hydrological projections based on climate scenarios was adopted. The A1B greenhouse gas (GHG) emission scenario built by the Intergovernmental Panel on Climate Change [IPCC, 2007] was chosen. It is considered as a median scenario between optimistic and pessimistic ones. The outputs of seven general circulation models (GCMs) were used. They provide daily precipitation, temperature and potential evapotranspiration scenarios for the 08/01/1961-07/31/1991 period chosen as a reference for current conditions (hereafter called present period and noted PST) and the 08/01/2046-07/31/2065 target period for future conditions (hereafter called future period and noted FUT). Since the spatial resolution of GCMs is too coarse to be used over the study basin, data downscaled at an $8 \times 8-\mathrm{km}^{2}$ resolution using the DSCLIM algorithm [Boé et al., 2006, 2007; Pagé et al., 2008; Quintana-Segui et al., 2010] were used.

For water withdrawals, the evolution scenarios designed within the Explore 2070 project [Chauveau et al., 2013] by BIPE were used.

\section{II.2. Modelling suite and methodology}

A modelling suite was set up to produce daily simulations of naturalized and influenced streamflows. The semi-distributed TGR model was used, which is composed of the GR4J conceptual rainfall-runoff model [Perrin et al., 2003] for each sub-catchment and a linear lag-and-route (LR) method to propagate the flow between the sub-catchments [Munier, 2009; Perrin et al., 2009].

The methodology for assessing the impacts of climate change involves several steps:

- First, the hydrological and hydraulic models were calibrated with naturalized flows on the period 1958-2009 using the SAFRAN observed meteorological data.

- Because downscaled GCM scenarios showed quite significant biases compared to observations over the present period, a quantile-quantile mapping method was applied to correcting precipitation, potential evapotranspiration and temperatures variables on a monthly basis. The aim is to fit the distributions of climate variables to the distributions of 
observations over PST and to apply the same transformation to simulated variables over FUT.

- The model was then forced with downscaled GCM variables in PST and FUT to quantify the possible hydrological trends on the Seine River Basin.

- A model simulating the current management rules of the reservoirs and a model of the withdrawals on the river were developed.

- Flow simulations were done under influenced conditions and the performance of the reservoirs management was assessed for PST and FUT using performance indicators related to flow objectives defined downstream the reservoirs by the stakeholders.

\section{II.3. Model assessement}

The average performance on the 25 stations is quite satisfactory: the model can quite well simulate the hydrological behaviour of the catchments including low-flow periods (see red curves in Figure 2(a) for results at Paris). To evaluate the performance of the integrated TGR model (with reservoir modelling), simulated flows were also compared with the historical observed flows at the gauging stations (see green curves in Figure 2(a) for the results at Paris). Flows simulated at the gauging stations downstream the reservoirs, at the reservoir inlets and outlets and also volumes of the reservoirs themselves, show that the model correctly mimics the current behaviour of the basin as influenced by the reservoirs, especially in the Paris region.

\section{IMPACTS OF CLIMATE CHANGE}

\section{III.1. Hydrological trends}

Seventy five percent of the simulations indicate a decrease in the average annual discharge between $15 \%$ and $30 \%$, for the FUT period compared to the PST period while $25 \%$ of the simulations show a slight increase or no trend. This result can be linked with the increase in temperature over the basin, meaning an increase in the evaporation losses.

The decrease in QMNA5 (minimum monthly mean discharge with five-year return period) and Q95 (the low-flow quantile exceeded $95 \%$ of the time) is the most striking result of the study. This decrease is observed for all simulations on the 25 stations. More than $75 \%$ of them show a decrease larger than $25 \%$. This evolution of QMNA5 and Q95 is related to the evolution of mean discharge during the dry months of the year (June to November). These results indicate that the increase of the severity and length of low-flow events may have strong impacts on future reservoir management during summer.

Regarding high flows, the evolutions seem uncertain, given the divergence between simulations: some of them show an increase of these hydrological descriptors, while the reverse can also be true for others. The winter high-flow period also indicates an uncertain evolution of monthly discharge: the simulations diverge and the spread is substantial.

\section{III.2. Impact of climate change on the efficiency of the reservoirs using current management rules}

The evolution of influenced flows (Figure 2(b), red curves) between PST and FUT periods looks quite similar to the evolution in non-influenced conditions (blue curves), i.e. consistent decrease of low flows and uncertain evolution of high flows. Interestingly, however, in low flow conditions, a clear gap appears in simulated ranges between PST and FUT periods, stressing the dramatic decrease of low flows between PST and FUT and the difficulty to maintain low flows at present levels with current management rules.

\section{ADAPTATION OF THE RESERVOIR MANAGEMENT}

Two options for improving and adapting the reservoir management and make it more robust under climate change were considered. At the tactical level, new objective filling curves of the reservoirs were designed under climate change

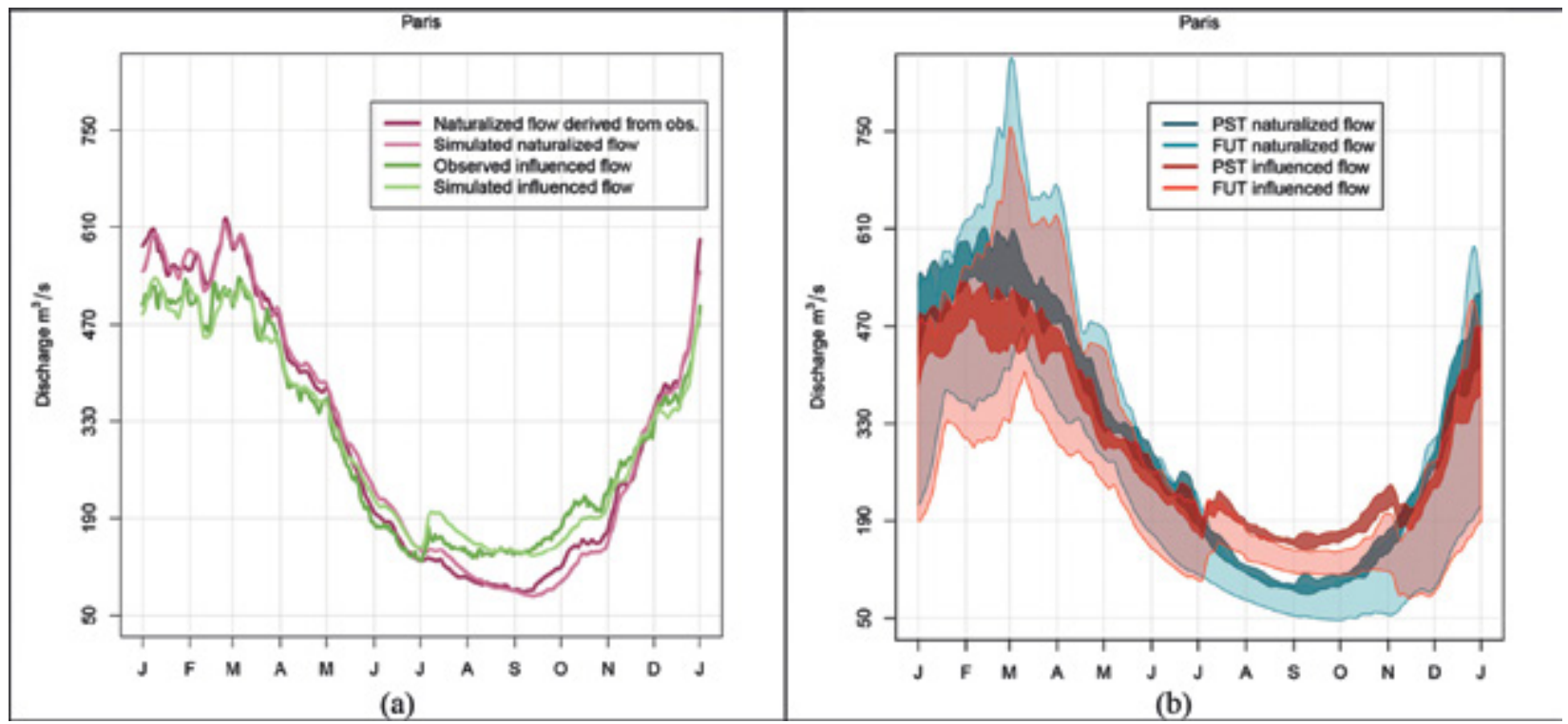

Figure 2 : Mean daily flows for the River Seine at Paris. (a) Influenced and naturalized flows are shown for the 1991-2008 period. (b) Evolution between present (PST) and future (FUT) conditions. Discharge simulations are obtained using the TGR model run with the 7 climate simulations. The shaded colours represent the band widths of the 7 simulations. Discharge simulations are shown in natural and influenced conditions. [after Dorchies et al., 2014] 
constraints. At the operational level, a centralized real-time controller for the four reservoirs was implemented by using a model predictive control driven with mid-term meteorological forecasts (9-day lead time). The two perspectives were tested separately and simultaneously to determine their respective levels of efficiency in a climate change adaptation perspective. They both have the particularity to explicitly take into account the downstream objectives described below.

\section{IV.1. Objectives and performance indicators used for benchmarking the reservoir management quality}

To evaluate the impact and efficiency of the reservoir management, flows are monitored at several gauging stations downstream from the four reservoirs. At each gauging station, several thresholds were chosen based on the operational practice of the services responsible for low-flow and flood management on the basin:

- In low-flow conditions, there are regulatory thresholds used to restrict water uses: Vigilance threshold (no restriction of water use), Alert threshold (30\% restriction), Reinforced Alert threshold (50\% restriction), and Crisis threshold (use of water is prohibited except a minimum use for drinking water).

- In high-flow conditions, the selected thresholds approximately correspond to three critical levels defined by the following colours: Yellow (No significant damage), Orange (Significant impact on community life and the safety of property and people), Red (Risk of major flood).

The reservoir management intends to maintain downstream flows within the limits defined by the thresholds, i.e. above the low-flow chosen threshold and below the chosen high-flow threshold. Performance indicators were calculated considering these objectives: the failure rate, the frequency of a failure event, the average length of a failure period [Hashimoto et al., 1982], and the vulnerability [Kjeldsen and Rosbjerg, 2004]. Formulas for these indicators are detailed in Dorchies et al. [2014].

\section{IV.2. Adaptation of tactical management: design of new objective filling curves}

The search for tactical management adaptation strategies was based on the method developed on the Manantali dam

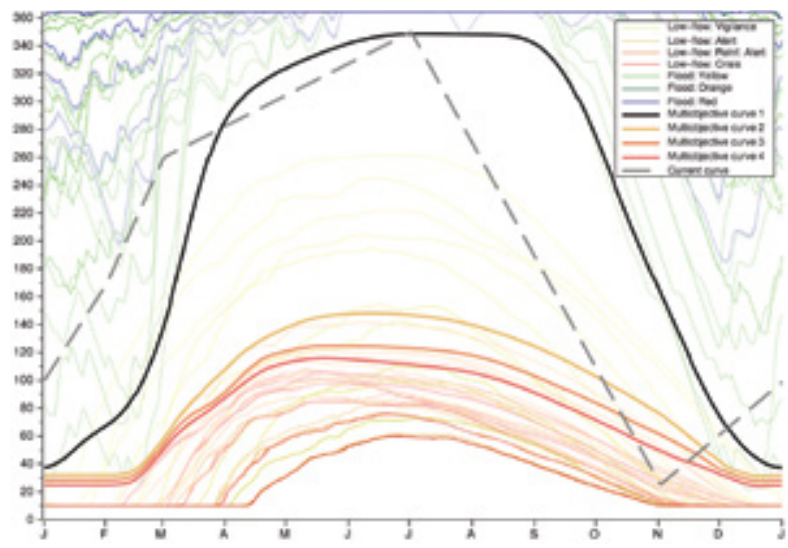

Figure 3 : Result of multi-objective optimisation of the filling curve for Lake Marne calculated from present (PST) simulated flows (7 GCMs scenarios x 1961-1991). Volumes ( $\left.\mathrm{hm}^{3}\right)$. Multi-objective filling curves in bold, current filling curve in dotted grey, low-flow and high-flow constraints in thin line. on the Senegal River [Bader, 1992]. This method provides, for one objective downstream one lake, the time series of optimal volumes which is statistically analysed for defining annual series of volume for different probabilities to achieve the objective (iso-frequency curves). This method can be classified among the Dynamic Programming algorithms, which are powerful tools for defining the optimal management on a known time series for one or few objectives. However, this method is not adapted to consider a large number of objectives especially when they are contradictory (like in the case of low-flow and flood management).

Instead of solving multiple objectives at the same time with the method used, it was chosen to combine a large set of iso-frequency mono-objective curves to define a multi-objective curve on each lake. The idea developed here is to draw a multi-objective curve that minimizes the risk for all the objectives at all the considered downstream stations. Figure 3 and Figure 4 show mono-objective iso-frequency curves of all objectives for a selection of downstream stations for Lake Marne. The iso-frequency curves are drawn with thin lines from yellow to red for low-flow objectives and from green to blue for high-flow objectives. The bold lines represent the result of the multi-objective optimization. The first one takes into account all the objectives. For the following multi-objective curves (resp. 2, 3 and 4), the optimization was done by removing successively the $1^{\text {st }}$, $2^{\text {nd }}$, and $3^{\text {rd }}$ low-flow objectives. Each curve corresponds to the volume required to support the respective downstream four thresholds (vigilance, alert, reinforced alert and crisis). According to the state of the reservoir and its ability to durably support a low-flow threshold, the manager targets the appropriate threshold at the downstream station.

The results with 1961-1991 and 2046-2065 simulations of all GCMs scenarios show that the new filling curve (noted Multi-objective curve 1) is shifted to the right relative to the current filling curve. The curves calculated for the four objectives from future (FUT) GCMs scenarios show a raising for each lake compared to PST period.

\section{IV.3. Adaptation of operational management: Use of Tree-Based Model Predictive Control}

For the real-time control, a centralized Tree-Based Model Predictive Control (TB-MPC) was developed [Raso et al.,

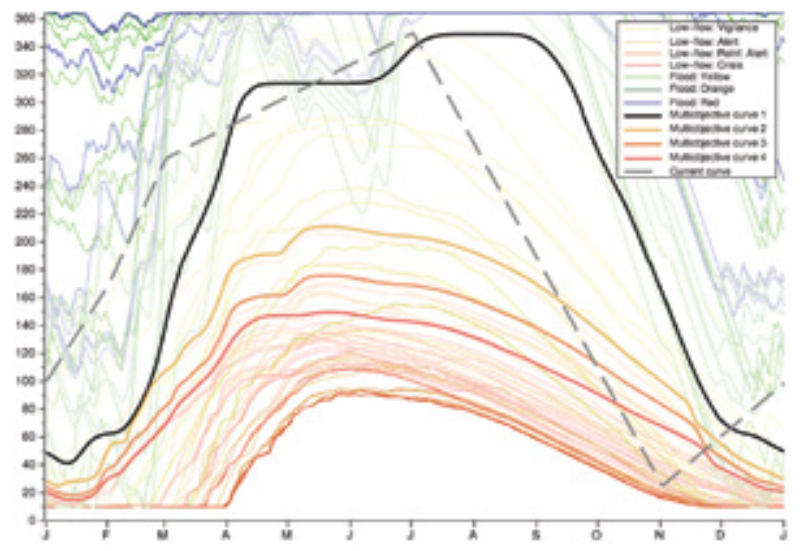

Figure 4 : Result of multi-objective optimisation of the filling curve for Lake Marne calculated from future (FUT) simulated flows (7 GCMs scenarios x 2046-2065). Volumes $\left(\mathrm{hm}^{3}\right)$. Multi-objective filling curves in bold, current filling curve in dotted grey, low-flow and high-flow constraints in thin line. 
2013; Maestre et al., 2013]. This method uses information available in real-time, including ensemble weather forecasting, to optimize an objective function that takes into account the costs associated to high and low flows over a finite receding horizon, using the integrated model to predict the evolution of the system in response to the forecasted inputs [Ficchí et $a l ., 2015]$. As the TB-MPC needs ensemble forecasts as input of the optimization, it was necessary to generate ensemble forecast corresponding to the GCMs simulations. A multivariate error model to produce "ensemble-dressing" of GCMs scenarios was used. The error model was calibrated on the error of real ensemble forecasts from ECMWF (9-day ahead forecasts available from 2005 to 2008). Several deterministic and probabilistic statistical scores were used for verifying that the generated ensemble forecasts have "realistic" errors and correct probabilistic skills.

\section{IV.4. Benchmarking the different management adaptations options}

Four management adaptation options mixing the current management and the proposed adapted management at operational and tactical levels were benchmarked using the performance indicators described above:

- Current management rules with current filling curve (hereafter CUR CFC);

- Current management rules with new multi-objective filling curves (hereafter CUR NFC);

- Tree-Based Model Predictive Control with current filling curve (hereafter TBMPC CFC);

- Tree-Based Model Predictive Control with new multi-objective filling curves (hereafter TBMPC NFC).

The model was run for these four management adaptation options using the $7 \mathrm{GCMs}$ simulations in present time (PST: 1961-1991) and future time (FUT: 2046-2065). The indicators below have been calculated for a set of 9 downstream monitoring stations and are represented in the form of boxplots combining data from the 7 GCM simulations and the 9 monitoring stations. Figure 5 compares each management adaptation in PST and FUT periods for the $2^{\text {nd }}$ low-flow threshold (Alert).

The current management rules with new filling curves (CUR NFC) is the best management option considering the failure rate and the events frequency. The management option that most reduces the vulnerability is the TBMPC NFC closely followed by CUR NFC. Managements using the new multi-objective filling curves show here their efficiency. However, none of the options fully manages to maintain future efficiency at the level of current conditions, showing the strong impact of climate change.

\section{CONCLUSIONS}

The Seine case study of the ClimAware project assessed and proposed adaptation strategies on the reservoir management considering climate change. A model was designed to simulate hydrology, hydraulic propagation, withdrawals and reservoir management in the Seine River Basin. In order to assess the reservoir management, performance indicators based on the low-flow and high-flow thresholds used by stakeholders on the catchment were calculated. The results of this assessment show that drought will be a major issue in the future.

Two adaptation measures were proposed at two different management levels. The first one intends to redesign the objective filling curves minimising the risk probability not to be able to achieve multiple objectives at some downstream gauging stations of the reservoirs in the future. This calculation is based on naturalized flow series that come from historical or generated data.

The second adaptation measure consists in using a real-time controller that intends to take into account all available data in real time. The Tree-Based Model Predictive Control (TBMPC) is among the most advanced and flexible
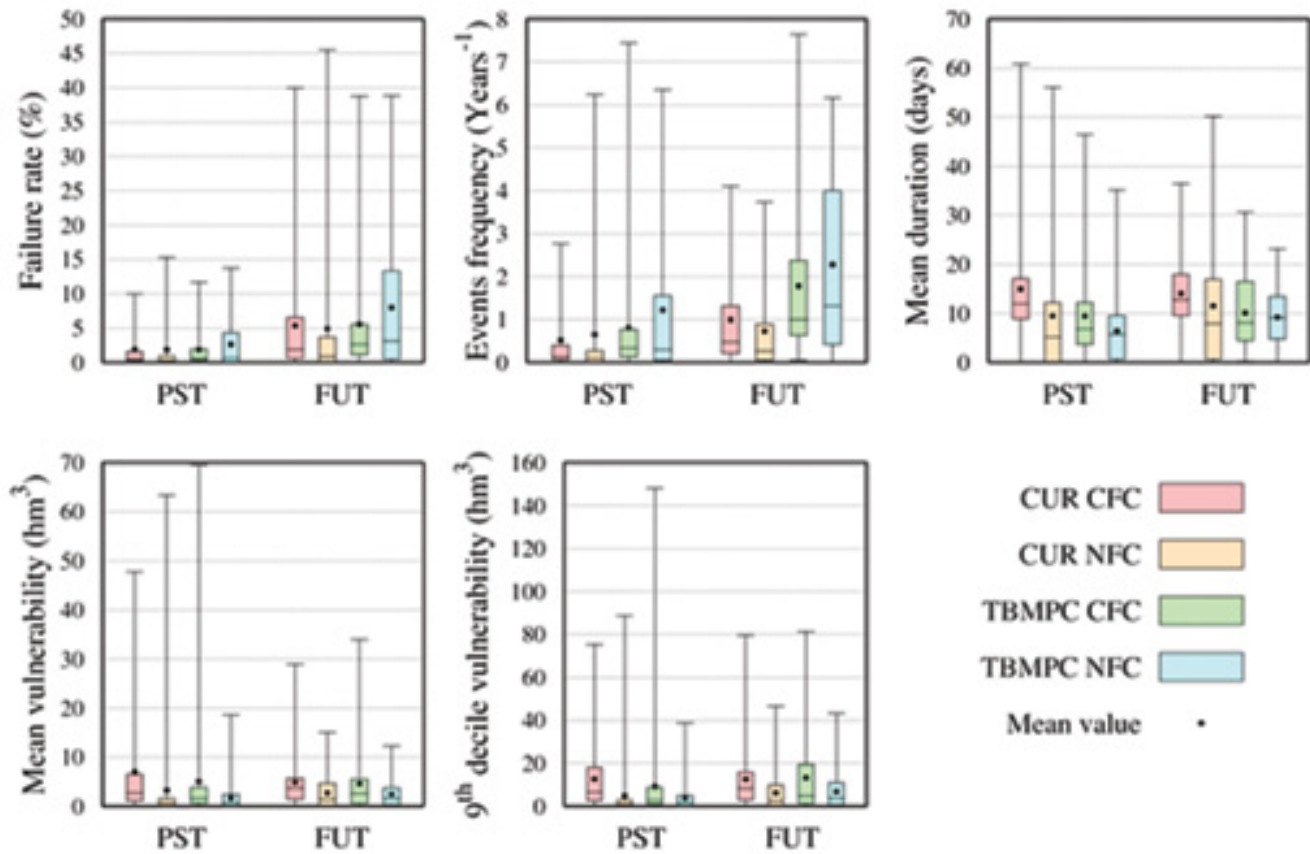

Figure 5 : Performance indicators for the $2^{\text {nd }}$ low-flow threshold (Alert) calculated from 7 GCMs scenarios in present (PST) and future (FUT) time for four management adaptations. The boxplots show the minimum, $1^{\text {st }}$ quartile, median value, $3^{\text {rd }}$ quartile and maximum values. The dot represents the mean value. 
kinds of real-time controller in this domain. This project is the first application of TBMPC to a multiple reservoir system, for both flood and drought objectives applied on long time series. Important difficulties were faced during the development of this real-time controller. One of them, which is not yet fully solved, is the weakness of the performance of the optimiser. For this reason the results obtained with TBMPC are not yet optimal.

The best results regarding the performance indicators in both present and future conditions are obtained with the management combining the new multi-objective filling curve and the current real-time rules using thresholds at stations close to the reservoirs. However, even with this management adaptation, the indicators show that climate change will impact low-flow periods. As an example, it can be expected that the alert threshold (which is the first threshold that causes restrictions in water uses) will be reached $5 \%$ of the time in the future instead of 1 or $2 \%$ in present time. To deal with this issue, the Seine Grands Lacs basin authority plans to develop, in partnership with the stakeholders in the basin, a program with two main objectives: (1) to assess the consequences of severe droughts and low-flow water events on current and future socio-economic activity needs and (2) to propose low-water level management strategies integrating the consequences of climate change at the scale of the basin.

\section{ACKNOWLEDGEMENTS}

This work was done within the Climaware project coordinated by the University of Kassel (www.uni-kassel.de/fb14/ wasserbau/CLIMAWARE/) and funded by the IWRM-Net programme (www.iwrm-net.eu). The authors thank SCHAPI for providing observed flow data, and Météo-France and Cerfacs for providing observed and downscaled climate data. Dr. Maria-Helena Ramos is thanked for her help in designing ensemble forecast data.

\section{REFERENCES}

Ambroise-Rendu M. (1997) - 1910 : La Seine en crue paralyse la capitale. La Houille Blanche. (8), 40-44.

BADER J. C. (1992) - Consignes de gestion du barrage à vocation multiple de Manantali. Détermination des cotes limites à respecter dans la retenue. Hydrologie Continentale. 7 (1), 3-12.

Boé J., L. Terray F. Habets And E. Martin (2006) - A simple statistical-dynamical downscaling scheme based on weather types and conditional resampling. Journal of Geophysical Research: Atmospheres. 111 (D23), D23106.

Boé J., Terray L., F. Habets F. And Martin E. (2007) Statistical and dynamical downscaling of the Seine basin climate for hydro-meteorological studies. International Journal of Climatology. 27 (12), 1643-1655.

Chauveau M., Chazot S., Perrin C., Bourgin P. Y., Sauquet E., Vidal J. P., Rouchy N., Martin E., David J., Norotte T., Maugis P. And De LacAZE X. (2013) - Quels impacts des changements climatiques sur les eaux de surface en France à l'horizon 2070 ?. La Houille Blanche. (4), 5-15.

Dorchies D., Thirel G., Jay-Allemand M., Chauveau M., Dehay F., Bourgin P.-Y., Perrin C., Jost C., Rizzoli J.-L., Demerlac S., Thepot R. (2014) - Climate change impacts on multi-objective reservoir management: case study on the Seine River basin, France. International Journal of River Basin Management. 12 (3), 1-19.
Ficchí A., Raso L., Dorchies D., Pianosi F., Malaterre P.-O., Van Overloop P.-J., Jay-Allemand M. (2015) - Optimal operation of the multi-reservoir system in the Seine River basin using deterministic and ensemble forecasts. Journal of Water Resources Planning and Management. 142 (1), doi 10.1061/ (ASCE)WR.1943-5452.0000571.

Hashimoto T., Stedinger J. R. And Loucks D. P. (1982) Reliability, resiliency, and vulnerability criteria for water resource system performance evaluation. Water Resources Research. 18 (1), 14-20.

Hydratec (2011) - Actualisation de la base de données des débits journaliers naturalisés (Update of the naturalized daily streamflow database). Rapport d'étude, Les Grands Lacs de Seine, Paris.

IPCC (2007) - Contribution of Working Groups I, II and III to the Fourth Assessment. Report of the Intergovernmental Panel on Climate Change, Geneva, Switzerland. 104 p.

Kueldsen T. R. And Rosbjerg D. (2004) - Choice of reliability, resilience and vulnerability estimators for risk assessments of water resources systems. Hydrological Sciences Journal-Journal Des Sciences Hydrologiques. 49 (5), 755-767.

Maestre J.M., Raso L., Van Overloop P.J., De Schutter B. (2013) - Distributed tree-based model predictive control on a drainage water system. Journal of Hydroinformatics. 15, 335.

Monteith J.L. (1965) - Evaporation and the environment. Proceedings of the XIXth Symposium of the Soc. for Exp. Biol., The state and Movement of water in living organisms, Swansea, Cambridge University Press, New-York. 205-234.

Munier S. (2009) - Modélisation intégrée des écoulements pour la gestion en temps réel d'un bassin versant anthropisé (Integrated flow modelling for real-time management of an influenced catchment). P.hD Thesis, AgroParisTech, Cemagref Montpellier. $180 \mathrm{p}$.

Pagé C., Terray L. And Bó́ J. (2008) - Projections climatiques à échelle fine sur la France pour le 21 ème siècle: les scénarii SCRATCH08, Cerfacs. $21 \mathrm{p}$.

Penman H. L. (1948) - Natural evaporation from open water, bare soil and grass. Proceedings of the Royal Society of London. 193, 120-145.

Perrin C., Michel C. And Andréassian V. (2003) - Improvement of a parsimonious model for streamflow simulation. Journal of Hydrology. 279 (1-4), 275-289.

Perrin C., Coron L., Fortier-Filion T. C., Munier S., Litrico X., Berthet L., Lerat J., Peschard J., Javelle P. And Andreassian V. (2009) - Analyse et modélisation des sous-bassins amont du bassin de la Seine (Analyzing and modelling upstream sub-catchments of the Seine River basin), Cemagref, UR HBAN (Antony) et UMR G-Eau (Montpellier), DIREN Ile-de-France. $76 \mathrm{p}$.

Quintana-Segui P., Le Moigne P., Durand Y., Martin E., Habets F., Baillon M., Canellas C., Franchisteguy L., Morel S. (2008) - Analysis of near-surface atmospheric variables: Validation of the SAFRAN analysis over France. Journal of Applied Meteorology and Climatology. 47 (1), 92-107.

Quintana Seguí P., Ribes A., Martin E., Habets F. And Boe J. (2010) - Comparison of three downscaling methods in simulating the impact of climate change on the hydrology of Mediterranean basins. Journal of Hydrology. 383 (1-2) : 111-124.

Raso L., Van De Giesen N., Stive P., Schwanenberg D. And VAN Overloop P. J. (2013) - Tree structure generation from ensemble forecasts for real time control. Hydrological Processes. 27 (1), 75-82.

Vidal J. P., Martin E., Franchisteguy L., Baillon M. And Soubeyroux J. M. (2010) - A 50-year high-resolution atmospheric reanalysis over France with the Safran system. International Journal of Climatology. 30 (11), 1627-1644. 